\title{
COMPARATIVE STUDY OF DIFFERENT COMBINED CYCLE POWER PLANT SCHEMES
}

\author{
Nikhil Dev and Rajesh Attri \\ Department of Mechanical Engineering, YMCA University of Science and \\ Technology, Faridabad, Haryana, India
}

\begin{abstract}
Combined Cycle Power Plants (CCPPs) are imperative for power generation with the capability for deciphering power shortage during peak and off peak hours. To perk up the recital of the plant, foremost locations of exergy losses are to be identified and analyzed. In the present work, exergetic analysis of a CCPP is carried out using the computer programming tool Engineering Equation Solver (EES). The effects of overall pressure ratio and turbine inlet temperature on the exergy destruction in the CPR are investigated. The results obtained are compared with that of simple gas turbine cycle power plant. During real time operation of CCPP exergy destruction in different components is associated with change in overall pressure ratio and turbine inlet temperature (TIT). Out of the total exergy destruction in the cycle it is the combustion chamber $(C C)$ which is responsible for the maximum exergy destruction. Nearly $60 \%$ of the total exergy is destroyed in CC. Results clearly show that with increase in complicacy of the power plant structure, irreversibility of the processes can be improved.
\end{abstract}

\section{KEYWORDS}

First-law, Second-law, Exergy Destruction, Gas Turbine Cycle, Combined Cycle Power Plant, Waste Heat Recovery Boiler.

\section{INTRODUCTION}

India is swift developing economy, with a need for independent and reliable supply of electricity and to be a power sufficient country is one of its prime concerns. At present total installed capacity of electricity generation in India by large scale power plants is 132,110.21 MW and per capita electricity consumption in 2005-06 was about $631 \mathrm{KWH}$ as calculated by CEA (Central Electricity Authority). This electric power consumption may be compared with other developed countries. Such as in U.S.A. per capita consumption of electric power is 13,338 KWH. The NEP (National Electricity Policy) decided that to make the country a developed country it is required the per capita consumption of electricity should be over 1000 units by 2012. Therefore, to achieve the objective of developed nation, large number of new power plant erection projects are currently in progress.

Power plants are numerous nature and out of these power plants TPP (thermal power plants) generates $64.7 \%$ of the total installed electricity power generation capacity. Because of their higher efficiency and reduced pollution emission gas turbine and CCPPs are becoming more and more attractive. India is spending a great amount of money to import the fuels, alternatively it could be used the in the development and growth of our country. In order to reduce power 
International Journal of Recent advances in Mechanical Engineering (IJMECH) Vol.4, No.4, November 2015

shortage efforts are required to improve the performance of existing plants. The present work is concentrated on determination of the exergy destruction of each component of the CCPP, and comparison of exergy destruction in exhaust gas and each component of the plant by varying overall CPR and turbine inlet temperature (TIT).

In recent times, exergy analysis has been used by scores of researchers for analysis of thermal systems, especially for power plants (Caton, 2000). Exergetic analysis is a part of thermodynamic analysis and it is based upon the second law of thermodynamics. Exergetic analysis takes care of energy, exergy and mass balance across each component. Therefore, with the help of this analysis it is possible to determine the magnitude of exergy and energy losses in different components. Exergetic analysis is based upon the entropy generation and it is stated in thermodynamics that every real time process increases the entropy of the universe. There are some real time processes which are responsible for entropy generation or exergy destruction. Dev et al (2012) stressed that it is the ambient temperature which decides the availability.

In literature (Dev et al., 2013a) exergy is defined as maximum possible work potential of a thermal system w.r.t. the ambient environment being considered as the datum state. Any flow stream with a temperature higher or lower than ambient is capable of performing some useful work. The potential of work is further dependent upon the difference in between system and surrounding. In a system entropy generation is due to heat transfer through finite temperature difference (Dev et al., 2013a), chemical reaction (Dev et al., 2013b), mechanical friction (Dev et al., 2013c), mixing of fluids at different temperature (Dev et al., 2013a) and vibration (Dev et al., 2013b). In a CCPP chemical reaction in between air and fuel takes place in CC. The potential of chemical reaction and exergy destruction is based upon the Gibbs free energy. Friction is present in flow path due to surface tension of fluids (Dev et al., 2015).

In the literature (Dev et al., 2014a; 2014b) it is also reported that reliability is also one of the most important parameter for the performance evaluation of the combined and cogeneration cycle power plants. One approach named as Graph Theoretic Approach (GTA) was used for the reliability analysis. This approach was extended further for the efficiency analysis also (Dev et al., 2015). The results obtained with that methodology were in comparison to the results obtained with exergetic analysis.

Butcher and Reddy (2007) carried out $2^{\text {nd }}$ law analysis of a WHRB (waste heat recovery boiler) for different design and operating parameters. WHRB is used for steam generation in different industries. Therefore, it is required to analyse its performance. The temperature profiles across WHRB, work output, $2^{\text {nd }}$ law efficiency and entropy generation were the main parameters to be analysed. In literature many computational techniques are suggested for the gas turbine (GT) analysis. Ahmadi and Dincer (2011) used Non-dominated Sorting Genetic Algorithm (NSGA-II) for efficiency and multi-objective optimization of a GT power plant. The results were to improve the cycle performance. Khaliq and Kaushik (2004) analysed performance of a GT cogeneration system using exergetic analysis. Second law analysis was found to be useful for improving the cycle performance. In another work Kotowicz and Bartela (2010) considered the more than one parameters for the performance analysis. They carried out thermo-economic analysis by using genetic algorithm based optimization programme. Poma et al. (2010) also used thermal and economic based design optimization to improve thermal system. Woudstra et al. (2010) and Regulagadda et al. (2010) conducted first and second law analysis for a coal-fired power plant. In the present analysis exergetic analysis of the CCPP system shown in Figure 1 is carried out for different operating parameters. 


\section{CCPP SYSTEM DESCRIPTION}

In the Figure 1 schematic diagram of a GT based CCPP with inlet air cooling and evaporative after cooling of the compressor discharge is represented. Ambient air is filtered, cooled and humidified in the air filter (AF), air humidifier (AH1) before it counter passes the inlet air to the low-pressure compressor (LPC) in the air cooler (AC), cooling the inlet air. Air at 3 is cooled to a temperature that is close to the wet bulb temperature at 1 . Compressed air from the low pressure compressor at 4 is cooled to 5 in an indirect intercooler using ambient humidified air that is humidified in the air humidifier (AH2) and has a lower temperature than ambient temperature. This cooled air enters the high-pressure compressor (HPC) and is compressed from state 5 to state 6 . The outlet air of HPC at 6 is heated in heat exchanger with the exhaust flue gas coming out from turbine. Ambient air at point 6 enters the regenerative type heat exchanger (HE), and it exchanges heat with power turbine (PT). Afterward exhaust at point 11 is heated at point 7 after gaining heat and it is supplied to $\mathrm{CC}$ where fuel i.e. CNG is burned, producing hot gases at point 8. The hot flue gases are expanded at point 9 in the high-pressure turbine (HPT) and achieve lower pressure and temperature before re-combusted in the re-heater, after which the reheat flue gases are expands through a PT to drive air compressor and turbo-generator. Part of the heat of hot exhaust gas is used in the HE, and part of this heat is utilized in the WHRB to generate steam, and hence to produce the process heat.

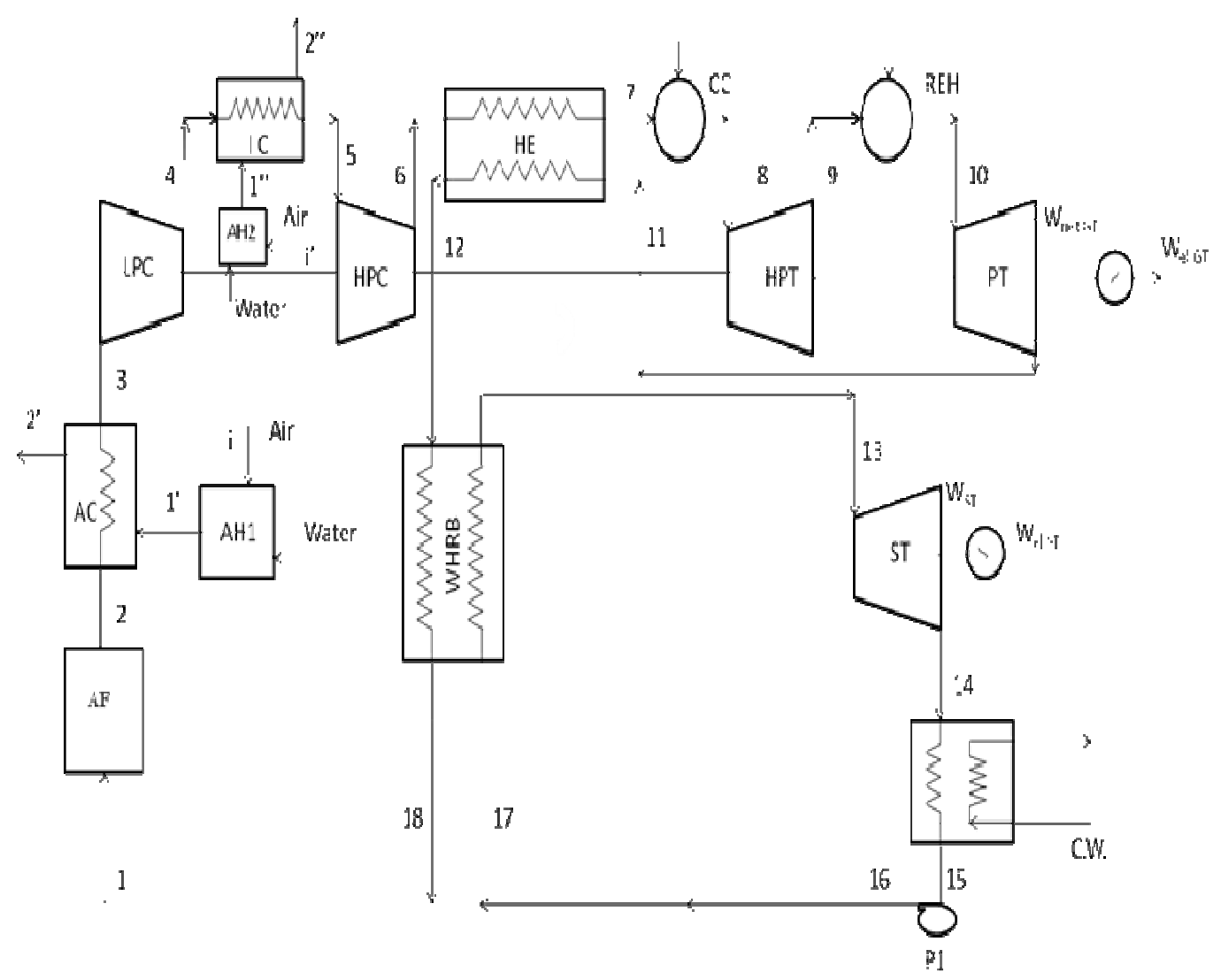

Fig. 1. Schematic line diagram of CCPP for the analysis 


\section{MATHEMATICAL MODEL}

Exergy analysis is the combination of the first and second laws of thermodynamics to evaluate the efficiencies of processes and devices. If the system operates in a steady-state, steady flow condition and all the nonreacting gases are arbitrarily assigned as zero thermo-mechanical enthalpy, entropy, and exergy at the condition of ambient pressure and temperature regardless of their chemical composition, then the entropy of mixing different gaseous components can be neglected, and the general exergy-balance equation is given by:

$$
\dot{E}_{W}=\sum_{i=1}^{n}\left(\dot{E}_{Q}\right) i+\sum_{\text {in }} \dot{m} e-\sum_{\text {out }} \dot{m e}-\dot{E}_{D}
$$

For single stream flow,

$$
\dot{E}_{W}=\left(\dot{E}_{Q}\right)+\dot{m} e_{\text {in }}-\dot{m} e_{o u t}-\dot{m} e_{D}
$$

The mathematical equations for different components of the CCPP are tabulated in Table 1.

Table 1 . The exergy destruction rate equations for plant components

\begin{tabular}{|l|l|}
\hline Components & Exergy Destruction Rate \\
\hline Air Compressor & $e_{D, A C}=e_{\text {in }}-e_{\text {out }}+\dot{W}_{A C}$ \\
\hline Combustion Chamber & $e_{D, C C}=e_{i n}+e_{f}-e_{\text {out }}$ \\
\hline Gas Turbine & $e_{D, G T}=\left(e_{\text {in }}-e_{\text {out }}\right)-\dot{W}_{G T}$ \\
\hline Heat Exchanger & $e_{D, H E}=\mathrm{m}_{\text {air }}\left(e_{a i}-e_{a o}\right)+\mathrm{m}_{g a s}\left(e_{g i}-e_{g o}\right)$ \\
\hline WHRB & $e_{D, W H R B}=\mathrm{m}_{\text {gas }}\left(e_{\text {gin }}-e_{\text {gout }}\right)-\mathrm{m}_{w}\left(e_{w o u t}-e_{\text {win }}\right)$ \\
\hline Air Filter & $e_{D, A F}=m_{a}\left(e_{a i}-e_{a o}\right)$ \\
\hline Air Humidifier & $e_{D, A H}=m_{a i} e_{a i}+m_{w} e_{w}-m_{a o} e_{a o}$ \\
\hline Steam Turbine & $e_{D, S T}=m_{s}\left(e_{\text {win }}-e_{\text {wout }}\right)-W_{S T}$ \\
\hline Feed Water Heater First & $e_{D, F W H 1}=m_{s 1} e_{14}+\left(m_{s}-m_{s 1}\right) e_{20}-m_{s} e_{21}$ \\
\hline Feed Water Heater Second & $e_{D, F W H 2}=m_{s 2} e_{15}+\left(m_{s}-m_{s 1}-m_{s 2}\right) e_{18}-\left(m_{s}-m_{s 1}\right.$ \\
\hline Condenser & $e_{D, C O N D}=\left(m_{s}-m_{s 1}\right)\left(e_{w i n}-e_{w o u t}\right)+m_{c w}\left(e_{c w i n}-e_{c w o}\right.$ \\
\hline Pump & $e_{D, P}=W_{P}+m_{s}\left(e_{w i n}-e_{\text {wout }}\right)$ \\
\hline
\end{tabular}




\section{RESULTS AND DISCUSSION}

In this work, the dependencies of first-law efficiency second-law efficiency and power-to-heat ratio (PHR) on the operating parameters: pressure ratio $\left(r_{p}\right)$ and turbine inlet temperature (TIT) is examined with energy and exergy balance across each component of the CCPP represented in Figure 1.

Table 2. Effect of CPR on efficiency and heat rate of the proposed CCPP and simple GT cycle

\begin{tabular}{|l|l|l|l|l|l|}
\hline $\begin{array}{l}\text { Pressure } \\
\text { Ratio }\end{array}$ & $\begin{array}{l}\mathbf{I}^{\text {st }} \\
\text { efficiency of law } \\
\text { gas turbine } \\
(\boldsymbol{\%})\end{array}$ & $\begin{array}{l}\mathbf{I I}^{\text {nd }} \\
\text { efficiency of law } \\
\text { gas turbine } \\
(\boldsymbol{\%})\end{array}$ & $\begin{array}{l}\mathbf{I}^{\text {st }} \\
\text { efficiency } \\
\text { of CCPP } \\
(\boldsymbol{\%})\end{array}$ & $\begin{array}{l}\mathbf{I I}^{\text {nd }} \text { law } \\
\text { efficiency } \\
\text { of CCPP } \\
(\boldsymbol{\%})\end{array}$ & $\begin{array}{l}\text { Power to } \\
\text { heat ratio }\end{array}$ \\
\hline 12 & 51.3 & 50.8 & 54.5 & 51 & 14.2 \\
\hline 20 & 52.1 & 51.1 & 56.2 & 51.8 & 12.8 \\
\hline 28 & 52.3 & 51.4 & 57 & 52 & 11.2 \\
\hline 36 & 52.4 & 51.5 & 57.4 & 52.1 & 10.1 \\
\hline 44 & 52.1 & 51 & 56.8 & 52 & 9.6 \\
\hline 52 & 52 & 50.5 & 56.3 & 51.9 & 8.9 \\
\hline
\end{tabular}

Table 2 shows the variation of PHR, first law efficiency, and second-law efficiency for the proposed CCPP and simple gas turbine cycle with variation in compressor CPR from 12 to 52 at $\mathrm{TIT}=1600 \mathrm{~K}$ and $\mathrm{RH}=60 \%$. As the CPR $\mathrm{r}_{\mathrm{p}}$ augment the compressor work is increased due to higher aerodynamic resistance forces. It results in raising the temperature at the compressor outlet due to absorption of higher work by the air. Air compressor and gas turbine are interconnected and interdependencies is in such a manner that both energy absorbed by air compressor and work generated by gas turbine are increased. Net result is dependent upon the increase in TIT also, if possible. Higher flow of the air is adjusted with the inlet guide vanes with increase in compression ratio. All the components of the cycle are interdependent. Therefore, as $r_{p}$ increases the air temperature at the creek of HE decreases, that reduces the facility of HE due to lesser amount of heat transfer. Hence, the flue gas temperature at $\mathrm{HE}$ outlet is augmented. As $r_{p}$ increases the power-to-heat ratio decreases, since at much higher CPR the process heat increases significantly. As the CPR increases, it is observed that air temperature at the inlet of the combustion chamber decreases due to decrease in capacity of the HE, domino effect in increasing the heat added. The ratio of net work output to the heat added represents the first-law efficiency of the cycle. Hence, as $r_{p}$ increases, the first-law and second law efficiencies of the CCPP is strong function at $r_{p}=36$ with the values of $57.4 \%$ and $52.1 \%$ respectively (Table 2). Results obtained are in line with the available in literature. Additional increase in $r_{p}$ reduces the efficiencies significantly because, at much higher CPRs, air mass flow rate is to be increased to fulfill the net requirement of work. Increase in air flow rate at compressor inlet increases fuel addition in combustion chamber. 
International Journal of Recent advances in Mechanical Engineering (IJMECH) Vol.4, No.4, November 2015

Table 3. Effect of TIT on efficiency and heat rate of the proposed CCPP and simple GT cycle

\begin{tabular}{|c|c|c|c|c|c|}
\hline TIT (K) & $\begin{array}{l}\text { Ist law } \\
\text { efficiency of gas } \\
\text { turbine (\%) }\end{array}$ & $\begin{array}{l}\text { Ind law } \\
\text { efficiency of } \\
\text { gas turbine } \\
(\boldsymbol{\%})\end{array}$ & $\begin{array}{l}\text { Ist law } \\
\text { efficiency of } \\
\text { CCPP(\%) }\end{array}$ & $\begin{array}{l}\text { IInd law } \\
\text { efficiency } \\
\text { of CCPP } \\
(\%)\end{array}$ & $\begin{array}{l}\text { Power to } \\
\text { heat ratio }\end{array}$ \\
\hline 1300 & 44.2 & 44 & 47 & 44.1 & 23.1 \\
\hline 1400 & 47.1 & 46.9 & 50.8 & 47 & 16.3 \\
\hline 1500 & 49.2 & 49 & 53.9 & 49.1 & 12.2 \\
\hline 1600 & 51.4 & 51.2 & 57 & 51.3 & 11.1 \\
\hline 1700 & 53.2 & 53 & 59.7 & 53.1 & 9.7 \\
\hline 1800 & 54.3 & 54.1 & 62 & 54.2 & 8.5 \\
\hline 1900 & 56.2 & 56.1 & 64.8 & 56.2 & 8 \\
\hline
\end{tabular}

Table 3 represents the deviation of the first-law, second-law efficiency, and PHR with the alteration in turbine inlet temperature at $\mathrm{r}_{\mathrm{p}}=36$ and $\mathrm{RH}=60 \%$ for the proposed CCPP and simple gas turbine cycle. TIT is one of the most important design parameter. Its limiting value is dependent upon the thermal stress bearing capacity of gas turbine blade material. First stage turbine blades are more affected with the flue gas temperature than higher stage. Generally compressor of the gas turbine cycle is with seventeen stages of compression aerodynamic and gas turbine is with three stages of expansion. For a designed CPR and ambient relative humidity, the first-law and second-law efficiencies are added up due to better utilization of waste heat and increase in efficiency of gas turbine cycle. The increase in designed value of TIT enhances the heat transfer rate by absorbing greater heat from turbine exhaust in the heat exchanger, and hence the temperature of air inlet to the combustion chamber would increase, which in turn would increase the mean temperature of heat addition that leads to reduction of the cycle heat addition. Therefore, cycle efficiency increases with an increase in TIT. But the power-to-heat ratio decreases noticeably for the reason that increase in generation of process heat is greater than the electric power output at higher TIT (Table 3 ).

Table 4. Results of CPR on exergy destruction in different components of the cycle for TIT $=1600 \mathrm{~K}, \varphi=$ $60 \%, \mathrm{P}_{\mathrm{atm}}=1$ bar, $\mathrm{T}_{\mathrm{atm}}=298 \mathrm{~K}$

\begin{tabular}{|c|c|c|c|c|c|c|c|c|c|}
\hline$r_{p}$ & $\begin{array}{c}e_{D, L P E} \\
(\mathbf{k J} / \mathbf{k g}\end{array}$ & $\begin{array}{c}e_{D, I} \\
(\mathbf{k J} / \mathbf{k g}\end{array}$ & $\begin{array}{c}e_{D, H P C} \\
(\mathbf{k J} / \mathbf{k g}\end{array}$ & $\begin{array}{c}e_{D, H E} \\
(\mathbf{k J} / \mathbf{k g})\end{array}$ & $\begin{array}{c}e_{D, C C} \\
(\mathbf{k J} / \mathbf{k g}\end{array}$ & $\begin{array}{c}e_{D, H P T} \\
(\mathbf{k J} / \mathbf{k g}\end{array}$ & $\begin{array}{c}e_{D, R H} \\
(\mathbf{k J} / \mathbf{k g})\end{array}$ & $\begin{array}{c}e_{D, P T} \\
(\mathbf{k J} / \mathbf{k g} \\
)\end{array}$ & $\begin{array}{c}e_{D, W H R B} \\
(\mathbf{k J} / \mathbf{k g} \\
)\end{array}$ \\
\hline 12 & 13.43 & 5.57 & 11.01 & 63.14 & 182.3 & 21.81 & 129.8 & 23.21 & 9.95 \\
\hline 20 & 14.89 & 7.64 & 13.13 & 60.07 & 204.2 & 27.69 & 161.4 & 27.32 & 13.61 \\
\hline 28 & 14.73 & 9.47 & 14.27 & 51.53 & 218 & 29.83 & 184.9 & 32.51 & 15.32 \\
\hline 36 & 15.69 & 10.83 & 14.93 & 41.27 & 228 & 35.17 & 198.7 & 32.58 & 17.48 \\
\hline 44 & 15.97 & 11.79 & 15.21 & 36.76 & 235.7 & 36.15 & 209.5 & 34.67 & 22.18 \\
\hline 52 & 17.82 & 12.63 & 15.72 & 35.21 & 242.1 & 43.32 & 218.5 & 40.17 & 22.17 \\
\hline
\end{tabular}

Table 4 gives an idea about the exergy destruction in each component of CCPP with the change in overall cycle pressure ratio (CPR) for TIT $=1600 \mathrm{~K}$ and $\mathrm{RH}=60 \%$. Results in the Table 4 represents exergy destruction in the combustion process and it is found that combustion process dominates the exergy destruction in CCPP, as expected; it represents over $60 \%$ of the total exergy destruction in the overall system. The exergy destruction in the regenerative HE is next in the 
International Journal of Recent advances in Mechanical Engineering (IJMECH) Vol.4, No.4, November 2015

line. As CPR increases, the exergy destruction in the $\mathrm{CC}$ and re-heater increases significantly. This is because the increase in CPR implies higher combustion pressure, which leads to larger destruction. As CPR increases the temperature at the inlet of the intercooler increases. Thus, the temperature gradient for heat transfer in it increases with higher CPR. This explains more exergy destruction in the intercooler for higher CPR. On the other hand, the exergy destruction in the regenerative HE decreases as the CPR increases. This is because the higher CPR consequences in the lower power turbine egress temperature as well as higher temperature at the inlet of the WHRB. As a result, the exergy destruction in the WHRB increases with higher CPR. As CPR increases, the exergy destruction in $\mathrm{WH}$ decreases because the gas temperature at the exit of the WHRB decreases for a given PP (pinch point) temperature. At a given TIT, as the CPR increases the exergy destruction in the compressor and turbine increases. The exergy destruction in $\mathrm{AH}$ and $\mathrm{AC}$ are constant because at all CPR it has been used for the same working condition. The exergy destruction in the evaporative after cooler increases as CPR increases.

Table 5. Effect of variation of TIT on exergy destruction in different components of the cycle for $r_{p}=36$,

$$
\varphi=60 \%, \mathrm{P}_{\mathrm{atm}}=1 \text { bar, } \mathrm{T}_{\mathrm{atm}}=298 \mathrm{~K}
$$

\begin{tabular}{|c|c|c|c|c|c|c|c|c|c|}
\hline $\begin{array}{l}\text { TIT } \\
\text { (K) }\end{array}$ & $\begin{array}{c}e_{D, L P E} \\
(\mathbf{k J} / \mathbf{k g} \\
)\end{array}$ & $\begin{array}{c}e_{D, I} \\
(\mathbf{k J} / \mathbf{k} \\
\mathbf{g})\end{array}$ & $\begin{array}{c}e_{D, H P C} \\
(\mathbf{k J} / \mathbf{k} \\
\mathbf{g})\end{array}$ & $\begin{array}{c}e_{D, H E} \\
(\mathbf{k J} / \mathbf{k} \\
\mathbf{g})\end{array}$ & $\begin{array}{c}e_{D, C C} \\
(\mathbf{k J} / \mathbf{k} \\
\mathbf{g})\end{array}$ & $\begin{array}{c}e_{D, H P T} \\
(\mathbf{k J} / \mathbf{k g} \\
)\end{array}$ & $\begin{array}{c}e_{D, R H} \\
(\mathbf{k J} / \mathbf{k} \\
\mathbf{g})\end{array}$ & $\begin{array}{c}e_{D, P T} \\
(\mathbf{k J} / \mathbf{k} \\
\mathbf{g})\end{array}$ & $\begin{array}{c}e_{D, W H R B} \\
(\mathbf{k J} / \mathbf{k} \\
\mathbf{g})\end{array}$ \\
\hline $\begin{array}{c}130 \\
0\end{array}$ & 16.1 & 10.73 & 14.93 & 26.41 & 208 & 35.32 & 189.2 & 29.86 & 6.13 \\
\hline $\begin{array}{c}140 \\
0\end{array}$ & 16.1 & 10.73 & 14.93 & 37.23 & 215.3 & 35.67 & 192.6 & 29.91 & 10.18 \\
\hline $\begin{array}{c}150 \\
0\end{array}$ & 16.1 & 10.73 & 14.93 & 39.71 & 221.9 & 35.42 & 195.7 & 31.83 & 13.12 \\
\hline $\begin{array}{c}160 \\
0\end{array}$ & 16.1 & 10.73 & 14.93 & 43.62 & 228 & 35.33 & 198.7 & 31.94 & 15.67 \\
\hline $\begin{array}{c}170 \\
0\end{array}$ & 16.1 & 10.73 & 14.93 & 53.74 & 233.7 & 35.36 & 201.5 & 33.41 & 20.96 \\
\hline $\begin{array}{c}180 \\
0 \\
\end{array}$ & 16.1 & 10.73 & 14.93 & 59.13 & 239.1 & 35.72 & 204.3 & 34.24 & 25.27 \\
\hline $\begin{array}{c}190 \\
0\end{array}$ & 16.1 & 10.73 & 14.93 & 64.65 & 244.3 & 35.83 & 207.2 & 31.78 & 29.96 \\
\hline
\end{tabular}

Results in Table 5 shows the disparity of exergy obliteration in every constituent of CCPP with the alteration in TIT at $r_{p}=36$ and $\mathrm{RH}=60 \%$. TIT is very much dependent upon the turbine blade material. For the higher cycle efficiency it is desired that TIT should be as high as possible. For higher TIT exergy destruction in the regenerative HE increases because the heat-transfer temperature gradient in it is also increased. It is discussed earlier that higher is the temperature difference amongst fluids more exergy is wasted. Constant heat transfer across higher temperature leads to higher exergy destruction in comparison to lower temperature gradient. It is due to higher degradation in energy quality. The exergy destruction in the $\mathrm{CC}$ and $\mathrm{RH}$ also increases because the logarithmic mean combustion temperature for the whole cycle increases. The exergy destruction in the WHRB increases because the temperature variation between the two heat exchanging fluids (flue gas and steam) increases, and for the designed CPR, more steam is generated by the WHRB with the higher TIT, which produces larger process heat. With increase in TIT the exergy destruction in WH decreases as the gas temperature at the exit of the WHRB decreases for a given pinch point temperature. The exergy destructions in AH, AC, EC, 
International Journal of Recent advances in Mechanical Engineering (IJMECH) Vol.4, No.4, November 2015

intercooler, AC, and power turbines are also shown in Table 5 and are constant. Again, CC and reheater are found to be a major source of irreversibility.

\section{CONCLUSION}

The proposed CCPP in the present work is more complex than the simple cycle gas turbine cycle. It will increase the cost of installation and operation. For the life time cycle cost analysis represents that major part of it is due to fuel cost. Therefore, increased efficiency of the proposed CCPP will compensate for the installation and operation cost. Exergy analysis gives better insight into causes of cycle inefficiencies. Therefore, it is recommended to carry out energy and exergy analysis of a CCPP for the better understanding of the system.

\section{Nomenclature}

$\begin{array}{ll}E & \text { Exergy rate }(\mathrm{kJ} / \mathrm{s}) \\ L H V & \text { Lower Heating Value } \\ R & \text { Gas constant }(\mathrm{kJ} / \mathrm{kg} \mathrm{K}) \\ T & \text { Absolute temperature }(\mathrm{K}) \\ T P & \text { Process heat temperature }\left({ }^{\circ} \mathrm{C}\right) \\ W & \text { Work }(\mathrm{kJ} / \mathrm{kg}(\text { dry air) }) \\ c_{p} & \text { Specific heat at constant pressure }(\mathrm{kJ} / \mathrm{kg} \mathrm{K}) \\ c_{v} & \text { Specific heat at constant volume }(\mathrm{kJ} / \mathrm{kg} \mathrm{K}) \\ e & \text { Specific exergy }(\mathrm{kJ} / \mathrm{kg}(\text { dry air) }) \\ e P & \text { Specific exergy associated with process heat }(\mathrm{kJ} / \mathrm{kg}) \\ g r & \text { Gibbs function of fuel }(\mathrm{kJ} / \mathrm{kg}) \\ h & \text { Enthalpy }(\mathrm{kJ} / \mathrm{kg}(\mathrm{dry} \text { air) } \\ h_{f} & \text { Enthalpy of saturated water at process steam pressure } \\ h_{g} & \text { Enthalpy of saturated vapor at process steam pressure } \\ m & \text { Mass }(\mathrm{kg}) \\ \mathrm{n} & \text { Number of moles } \\ p & \text { Pressure }(\text { bar }) \\ \mathrm{Q}_{\mathrm{p}} & \text { Process heat }(\mathrm{kJ} / \mathrm{kg}(\mathrm{dry} \text { air) }) \\ r_{p} & \text { Compression ratio } \\ s & \text { Entropy }(\mathrm{kJ} / \mathrm{kg} \mathrm{K}) \\ t & \text { Temperature }\left({ }^{\circ} \mathrm{C}\right) \\ v & \text { Specific volume }\left(\mathrm{m}^{3} / \mathrm{kg}\right)\end{array}$

\section{Greek Symbols}

$\omega$

$\varphi$

$\varepsilon$

$\eta$

$\gamma$

\section{Subscripts}

$\mathrm{AC}$

$\mathrm{CC}$

$D$

GT

$P$
Humidity ratio ( $\mathrm{kg}$ of water vapor per kg of dry air)

Relative humidity (\%)

Effectiveness (\%)

Efficiency (\%)

Specific heat ratio

Air compressor

Combustion chamber

Destruction

Gas Turbine

Product 
International Journal of Recent advances in Mechanical Engineering (IJMECH) Vol.4, No.4, November 2015

$\begin{array}{ll}Q & \text { Heat } \\ R & \text { Regenerator } \\ \text { SG } & \text { Steam Generator } \\ W & \text { Work } \\ a & \text { Ambient air } \\ a v & \text { Average } \\ f & \text { Fuel } \\ g & \text { Gas } \\ i & \text { Inlet } \\ l & \text { Liquid } \\ o & \text { Outlet } \\ \text { sat } & \text { Saturated } \\ v & \text { Water vapor } \\ w & \text { Water } \\ 1,2,3, \ldots & \text { State points in the cycle }\end{array}$

\section{REFERENCES}

[1] Ahmadi P., Dincer I., (2011). Thermodynamic and exergoenvironmental analyses, and multiobjective optimization of a gas turbine power plant. Applied Thermal Engineering. 31, 2529-2540.

[2] Butcher, C. J., Reddy, B. V. (2007). Second law analysis of a waste heat recovery based power generation system. International Journal of Heat and Mass Transfer. 50, 2355-2363.

[3] Caton, J. A. (2000). A review of investigations using second law of thermodynamics to study internal combustion engines. SAE 2000-01-1081.

[4] Dev, N., Attri, R., Goyal G. K., Kumar, N. (2013a). Exergetic Analysis of Combined Cycle Power Plant with Single Steam Extraction. ASME Gas Turbine India Conference, Bangalore.

[5] Dev, N., Attri, R., Goyal G. K., Kumar, N. (2013b) Graph Theoretic Analysis of Advance Combined Cycle Power Plants Alternatives with Latest Gas Turbines. ASME Gas Turbine India Conference, Bangalore.

[6] Dev, N., Attri, R., Sharma, V., Kumar, K. (2013c). Economic analysis of a cogeneration cycle power plant. International Journal of Management and Behavioural Sciences. 4, 184-189.

[7] Dev, N., Attri, R. (2013). System modelling and analysis of a Gas turbine power plant using graph theoretic approach. International Journal of Energy, Environment and Economics. 21(1), 21-33.

[8] Dev, N., Samsher, Kachhwaha, S. S., Attri, R. (2012). GTA based frame work for evaluating the role of design parameters in Cogeneration Cycle Power plant efficiency. Ain Shames Engineering Journal. 4(2), 273-284.

[9] Dev N, Samsher, Kachhwaha SS and Attri R (2014a). Development of Reliability Index for Combined Cycle Power Plant using graph theoretic approach. Ain Shams Engineering Journal. 5, 193-203.

[10] Dev N, Samsher, Kachhwaha SS and Attri R, (2014b). Development of Reliability Index for Cogeneration Cycle Power Plant Using Graph Theoretic approach. International Journal of Systems Assurance Engineering and Management. DOI 10.1007/s13198-014-0235-4.

[11] Dev N, Samsher, Kachhwaha SS and Attri R. (2015). GTA Modelling of combined cycle power plant efficiency analysis. Ain Shams Engineering Journal. vol 6 (1), 217-237.

[12] Khaliq, A., Kaushik, S. C. (2004). Thermodynamic performance evaluation of combustion gas turbine cogeneration system with reheat. Applied Thermal Engineering. 24, 1785-1795.

[13] Kotowicz, J., Bartela, L. (2010). The influence of economic parameters on the optimal values of the design variables of a combined cycle plant. Energy. 35, 911-919.

[14] Poma, C., Verda, V., Consonni, S. (2010). Design and performance evaluation of a waste-to-energy plant integrated with a combined cycle. Energy. 35, 786-793.

[15] Regulagadda, P., Dincer, I., Naterer, G. F. (2010). Exergy analysis of a thermal power plant with measured boiler and turbine losses. Applied Thermal Engineering. 30, 970-976.

[16] Woudstra, N., Woudstra, T., Pirone, A., Van der Stelt, T. (2010). Thermodynamic evaluation of combined cycle plants. Energy Conversation Management. 51, 1099-1110. 